\title{
¿La educación literaria de los futuros maestros es suficiente para ejercer de mediadores de las nuevas generaciones?'
}

\author{
A educação literária dos futuros professores \\ é suficiente para serem mediadores das novas \\ gerações?
}

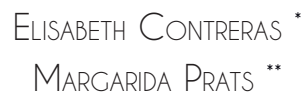

Resumen: En este artículo se aborda un desafío relacionado con la formación literaria de los estudiantes de magisterio y su capacitación para ejercer de mediadores entre las obras literarias y las nuevas generaciones. Partimos del perfil lector de los españoles, según las últimas encuestas del C.I.S., y de los estudios precedentes sobre el perfil literario de los futuros maestros. Seguidamente, presentamos nuestra experiencia con cuatro grupos de los grados de Educación Infantil y Primaria de la Universidad de Barcelona. Nos centramos en su perfil literario y en sus valoraciones de las actividades de educación literaria. Finalmente presentamos cuatro tipos de actividades, implementadas en los grupos citados, que giran en torno a la incorporación de herramientas digitales en la enseñanza-aprendizaje de la literatura.

Palabras clave: Educación literaria, perfil lector, herramientas digitales, estudiantes de magisterio

Resumo: Este artigo aborda um desafio relacionado à formação literária dos estudantes de magistério e sua capacitação para exercer como mediadores entre as obras literárias e a novas gerações. Partimos do perfil leitor dos espanhóis, de acordo com as últimas pesquisas do cis, e de estudos precedentes sobre o perfil literário dos futuros professores. Em seguida, apresentamos nossa experiência com quatro grupos dos cursos de educação infantil e primária da universidade de barcelona. Centramo-nos em seu perfil literário e em suas valorações acerca das atividades de educação literária. Finalmente apresentamos quatro tipos de atividades, implementadas nos grupos citados, que se relacionam à incorporação de ferramentas digitais no ensino aprendizagem da literatura. Palavras-chave: educação literária, perfil leitor, ferramentas digitais.

\footnotetext{
1 Este artículo está en relación con la línea de investigación del proyecto 2014SGR180 del grupo de investigación "Formació Receptora. Anàlisi de Competències" (FRAC) de la Universidad de Barcelona.

* Profesora del Departamento de Didáctica de la Lengua y la Literatura. Facultad de Educación.

** Profesora del Departamento de Didáctica de la Lengua y la Literatura. Facultad de Educación.
} 


\section{ntroducción}

Como miembros del grupo de investigación "Recepción y Formación Lectora: Análisis de Competencias (FRAC) del Departamento de Didáctica de la Lengua y la Literatura de la Universidad de Barcelona desarrollamos investigaciones centradas en el amplio marco de la actividad del lector/receptor. En este trabajo nos hemos centrado en el análisis de los perfiles lectores de estudiantes de magisterio, en sus vínculos de las experiencias como discentes con la lectura literaria y en la formación del lector, y en el uso de textualidades multimodales, a través de herramientas digitales como las aplicaciones para dispositivos móviles y las web 2.0, para mejorar tanto la competencias literaria y digital como la actitud hacia la literatura.

En enero de 2015, el Centro de Investigaciones Sociológicas (C.I.S.) de España anunciaba que según sus últimas encuestas solamente un tercio de los españoles lee libros todos los días o casi todos los días de la semana; el 58\% lee de manera más esporádica y un $35 \%$ no lee nunca o casi nunca. Con lo cual España tendría una población lectora de un $63 \%$, frente al $70 \%$ de población lectora de media en Europa. Los españoles leen una media de 8,69 libros al año y compran 5,69 ejemplares de media.

A pesar de lo que se tiende a creer, el perfil lector mayoritario de los estudiantes universitarios españoles no se aleja demasiado de la radiografía que muestra el C.I.S., tal y como se constata en este y otros estudios recientes. En este artículo, centramos la reflexión en los estudiantes del grado de Educación Infantil y Primaria de la Universidad de Barcelona.

En los últimos años, se han publicado varios estudios que demuestran que los futuros maestros tienen un bagaje literario pobre y un déficit de hábitos lectores que conllevan una falta de competencia literaria (Larrañaga, Yubero, Cerillo, 2008; Díaz Armas, 2008; Colomer, Munita, 2013). Ante esta situación, difícilmente los futuros maestros podrán convertirse en buenos mediadores de la lectura ni podrán contagiar el placer por la literatura; nunca provocarán el llamado efecto espejo (Manresa, 2009) en sus alumnos. Sin embargo, en los planes de estudio de los grados de Educación Infantil y Primaria, normalmente, la formación literaria que se ofrece a los alumnos es una asignatura obligatoria semestral de didáctica de la literatura infantil y juvenil, enfocada a dotar a los estudiantes de estrategias y recursos didácticos para llevar al aula las obras literarias; de 
manera que "tendemos a dirigirnos a unos sujetos ideales con un discurso didáctico que circula en paralelo a sus posibilidades de diálogo e interiorización" (Colomer, Munita, 2013, p.38).

En distintas sesiones de auto-reflexión con alumnos del grado de Educación Primaria y de Educación Infantil de la Facultad de Educación de la Universidad de Barcelona se han tratado y valorado sus hábitos lectores y su perfil literario, con distintos objetivos. En primer lugar, conseguir tener una idea más clara del perfil literario que hay en las aulas de magisterio, es decir, saber qué tipo de lector enseñará a leer a los niños de mañana. No solamente tenemos la voluntad de hacer una instantánea que devenga en un estudio descriptivo de la situación que ya se intuye, sino para conocer la verdadera dimensión de una problemática, que curso tras curso se impone al plan docente de la única asignatura de literatura de los grados de Educación Infantil y Primaria, y poder diseñar estrategias y actividades enfocadas a paliar unas carencias insalvables para futuros mediadores literarios. Asimismo, las sesiones de auto-reflexión sobre cuestiones literarias también tienen como objetivo inducir a los alumnos a hacer autocrítica y a concienciarlos de la trascendencia que tiene su educación literaria en su futura tarea como maestros.

\section{Lector literario y hábitos de lectura}

Durante el curso 2014-2015 organizamos tres sesiones en distintos grupos de distintas asignaturas de didáctica de la lengua y la literatura en el grado de Educación Infantil y Primaria, para reflexionar sobre cuestiones literarias. Estas sesiones las llamamos "Clubes de lectura". En éstas los alumnos se sientan haciendo un círculo, para facilitar la comunicación entre ellos, y cada uno trae un libro para recomendar al resto de la clase, ya sea para regalar por Navidad (primer semestre) o para comprar el día del Libro (segundo semestre). En todas las ocasiones, la profesora inicia la sesión presentando algún libro significativo en su vida profesional o personal. A partir de esta primera intervención, uno a uno, cada alumno va presentando su propuesta en unos pocos minutos. Después de la breve presentación, la profesora, como moderadora de la sesión, intenta crear diálogo entre los alumnos, preguntandoles quiénes lo han leído y en tal caso, qué les ha parecido, o, por ejemplo, si conocen otras obras del mismo autor/a. 
Si hay un interés generalizado por el libro la profesora ofrece otros títulos que compartan un mismo tema, autor, tipo de personaje, etc., con el objetivo de abrir el panorama literario de los alumnos a partir de ofrecer sutilmente nuevos títulos, autores o géneros, en los que primen siempre la calidad literaria.

Si analizamos las obras propuestas por los alumnos observamos que predomina casi exclusivamente el género narrativo, especialmente la novela. Entre las obras más recomendadas han aparecido Los juegos del hambre de Suzanne Collins, Divergente de Veronica Roth, la saga de Harry Potter de J. K. Rowling, Bajo la misma estrella, de John Green, La sombra del viento, de Ruíz Zafón, varias novelas de Albert Espinosa, las novelas de Federico Moccia y El diario de Ana Frank. Si analizamos la lista de títulos que los alumnos han recomendado a sus compañeros, se puede ver una clara prioridad por los best-sellers que han sido adaptados para el cine o la televisión. De manera que, además, de las ya mencionadas Juegos del hambre, Divergente, Harry Potter, Bajo la misma estrella o las novelas de Federico Moccia, debemos añadir otras como Crepúsculo, de Stephenie Meier, Cincuenta sombras de Grey, de E. L. James, las novelas de Dan Brown, El niño del pijama de raya,s de John Boyne, El médico. de Noah Gordon, El abuelo que saltó por la ventana y se largó, de Jonas Jonasson, Cometas en el ciel,o de Khaled Hosseini y La soledad de los números primos, de Paolo Giordano. Los superventas de carácter nacional también ocupan un lugar muy importante en las biografías literarias de los futuros maestros.

Antes de la sesión de reflexión se insiste mucho en que no se trata de recomendar obras de literatura infantil y/o juvenil, aunque la asignatura que acoge el "Club de lectura" se encargue de ésta, porque el objetivo es conocer su perfil literario de adulto. A pesar de las recomendaciones un grupo muy destacado de estudiantes recomiendan novelas juveniles que leyeron en sus años de secundaria.

Aunque pueda sorprender los clásicos universales y los clásicos contemporáneos catalanes y españoles, básicamente, tienen una buena acogida entre los alumnos. La totalidad de estos autores los han leído por recomendación escolar, pero han gozado de sus lecturas.

Otro grupo de obras literarias significativo en los gustos literarios son las que hemos llamado para la ocasión "novelas contemporáneas", sin un subgénero determinado. Esta etiqueta corresponde a un cajón de sastre donde hemos inclui- 
do escritores muy distintos entre si y temáticas varias. La mayoría de estas obras se las han comprado ellos mismos o se las ha regalado o prestado un amigo.

Otro género con muchos adeptos es el de las biografías y autobiografías, normalmente de deportistas de élite, y en algunas ocasiones de maestros. Muy a menudo los alumnos presentan estas obras, especialmente las escritas por deportistas, como si se tratara de libros de autoayuda, que les han motivado u orientado en determinado momento de la vida. El último gran género es la novela negra.

Éstos serían los géneros y subgéneros más leídos por los estudiantes, pero no son los únicos, pues algunos alumnos han optado por novela erótico-amorosa, ensayos de temática educativa y algún libro de autoayuda. Unos pocos han dejado testimonio de novela histórica, de ciencia ficción. Y finalmente, un par de alumnos han presentado un recopilatorio de cuentos y un sólo alumno se ha declarado lector de poesía.

Más de la mitad de estos estudiantes ha confesado leer entre 1 y 5 libros al año, concentrados casi todos en período vacacional. Son bastantes quienes leen entre 6 y 10 obras anuales, incluyendo la bibliografía recomendada y obligatoria de la universidad. En menor medida, destacan quienes leen entre 11 y 15 libros. Las opciones de leer más de 15 libros anuales y la de no leer nunca son claramente minoritarias.

Asimismo, debe destacarse que una gran mayoría de los estudiantes ha conocido el libro presentado gracias a la escuela, porque lo obligaron a leerlo. Aunque cuando se debate en clase sobre si se debe obligar a leer en la escuela, la mayoría de alumnos está en desacuerdo de una manera más o menos argumentada, pero siempre contundente, es verdad que la mayoría ha admitido que fue la escuela quien le recomendó la lectura y que en "aquella" ocasión había sido positivo, porque de otro modo no hubieran dado con el libro. También es cierto que, casi todos se apresaban a decir que había sido la única lectura obligatoria que les había gustado. Fuera del ámbito escolar, muchos estudiantes leyeron el libro por recomendación de un amigo o un familiar, en cuyo caso los hermanos tienen un papel muy destacado. Son una minoría quienes encuentran el libro por su propia cuenta y normalmente lo hacen en unos grandes almacenes.

Finalmente, cuando se les cuestiona por qué les ha gustado el libro que recomiendan, todos los estudiantes, sin excepción, responden o bien, porque les "engancha", es decir, que la tensión narrativa y la intriga les mantienen en vilo; 
o bien, porque se identifican con alguno de sus personajes, normalmente, el protagonista.

En un estudio sobre el itinerario lector en la adolescencia, la profesora Ana Díaz-Plaja (Díaz-Plaja, 2008) analiza y clasifica las obras literarias que leen los jóvenes españoles de entre 12 y 18 años. Díaz-Plaja diferencia las lecturas de los adolescentes entre alta cultura -normalmente, vinculadas a la biblioteca del centro escolar o a iniciativas del profesorado- y baja cultura -entendida como producto de consumo, de poca calidad literaria, que se encuentran en los supermercados y grandes almacenes.

A pesar de que la clasificación que hemos establecido nosotras es más restringida de la que hizo en 2008 la profesora Díaz-Plaja (Díaz-Plaja, 2008), el perfil literario de los estudiantes de secundaria y el perfil literario de los alumnos de magisterio mantienen paralelismos muy significativos, a pesar de que estos últimos ya han cursado entre 2 y 3 años en la Universidad y se supondría que sus horizontes culturales y literarios deberían haber sufrido una apertura importante. Sin embargo, su lector literario mantiene las mismas preferencias: leen literatura canónica por recomendación escolar y tienen preferencia por los best-sellers, que tienen sus adaptaciones para el cine o la televisión.

Cuando reflexionamos con los alumnos sobre su lector literario y sus hábitos de lectura en segundo o tercer curso universitario y constatamos que sus referentes literarios son en gran medida productos comerciales, estrechamente vinculados al campo audiovisual, podemos afirmar que hemos fracasado en su educación literaria: "El best-seller com la darrera etapa del camí suposaria una capitulació definitiva, la confirmació del fracás dels esforços per formar un bon lector capaç d'apreciar la literatura." (Margallo, 2008, p.221). Por este motivo se hace difícil o prácticamente imposible, que la formación en didáctica de la literatura que adquieren en los grados de Educación Infantil y Primaria pueda suplir las lagunas de formación literaria que tienen y les permita devenir los mediadores literarios que las nuevas generaciones necesitan. La formación literaria que reciben los estudiantes en los grados de magisterio se reduce, normalmente, a una asignatura obligatoria semestral y se les presupone una formación literaria sólida, a partir de la cual se les orienta con recursos y estrategias didácticas para convertirlos en excelentes mediadores literarios. Sin embargo, quizá esta formación tendría que repensarse, reorientarse y ofrecer una educación literaria 
pensando en los propios alumnos como lectores y no solamente como futuros maestros de literatura.

Nuestros futuros maestros presentan un perfil literario pobre, marcado por lecturas de poca calidad literaria, tienen poco hábito de lectura y en consecuencia sus criterios para valorar y juzgar una obra son muy superficiales, consecuencia de la poca experiencia lectora que tienen. Parece evidente que los estudiantes terminan la etapa obligatoria sin haber adquirido los principios de la lectura culta y las herramientas necesarias para afrontar cualquier tipo de lectura, con lo cual no podemos dar por concluida su formación literaria básica, al menos en grados universitarios en los que su formación estética y literaria tendrá una trascendencia profesional muy importante. Si obviamos estas carencias no solamente habremos fracasado en su formación literaria, sino que perpetuaremos esta situación en las nuevas generaciones que serán sus futuros alumnos, y quizá dentro de unas décadas la formación estética de la población será residual y los hábitos de lectura, puramente anecdóticos.

Ahora bien, "no n'hi ha prou de saber què saben (i què no saben) els alumnes; no n'hi ha prou de saber què ens agradaria que sabessin: és necessari estar en condicions de crear els ponts necessaris per recórrer amb ells el camí d'una riba a l'altra." (Jover, 2007, p.90). Debemos conocer y analizar la realidad del perfil literario de nuestros estudiantes y sus hábitos de lectura, saber cuál es la situación para poder tomar medidas al respecto y revertir o enmendar la situación.

\section{Buenas y malas experiencias literarias}

Más allá de conocer la situación, para ser honestos con los alumnos y con nosotros mismos y consecuentes en nuestras tareas docentes, es importante conocer el origen: qué actuaciones o experiencias han dado lugar a la realidad literaria que tenemos. Por ello es importante reflexionar con los alumnos también acerca de las experiencias, buenas y malas, que los han conducido a ser el tipo de lector que son. En los grados de Educación Infantil y Primaria, la reflexión sobre las prácticas docentes que han vivido como alumnos adquiere todavía más trascendencia porque muy a menudo los docentes acaban repitiendo las actuaciones que han recibido, con lo cual es importante discernir entre las buenas experiencias de las malas. 
Es fundamental partir del bagaje de recuerdos y vivencias, vinculados a relaciones afectivas con personas, a una o varias lenguas y culturas, a las experiencias como lectores y espectadores con referentes intertextuales, que aportan los estudiantes. Compartir dicho bagaje en el inicio de los cursos de literatura infantil contribuye a compartir reflexiones sobre la práctica docente universitaria. (Díaz-Plaja, Prats, 2013: 20)

Si se ponen en común experiencias literarias positivas que han vivido durante su infancia y adolescencia, destacan actuaciones de carácter vivencial, es decir, actividades en las que la literatura se ha aproximado o integrado en su realidad cotidiana, gracias la mediación de alguien especial. Así, los estudiantes destacan como buenas experiencias literarias, la lectura de obras que después han vivido en una representación teatral o han visto su adaptación al cine o a la televisión, medios culturales que han marcado profundamente su infancia. También ocupan un lugar destacado las buenas lecturas: aquellos libros cuyas lecturas por si solas ya les ha supuesto una grata experiencia. Las experiencias en las que la mediación de alguien más o menos experto tiene un papel destacado, se encuentran entre las más mencionadas. De este modo, las lecturas compartidas con algún miembro de la familia antes de ir a dormir o los cuentacuentos de bibliotecas y colegios ocupan un lugar destacado en la memoria del alumnado. Sin embargo, actividades que pudieran hacerse de manera puntual y celebraciones de fechas señaladas como Sant Jordi, la visita de algún escritor, excursiones por rutas literarias, o elementos estructurales en la formación literaria, como la biblioteca, un buen profesor o clases más participativas, apenas se mencionan, ya sea porque no las consideran buenas experiencias, ya sea porque no han tenido oportunidad de vivirlas.

A la hora de detectar las malas experiencias literarias en las aulas hay bastante consenso entre los estudiantes y todas ellas están relacionadas al ámbito escolar. Una gran mayoría denuncia malas lecturas, inapropiadas o aburridas; seguidas por lecturas en voz alta delante de los demás compañeros, actividades poco atractivas, la obligación de leer unos libros determinados, tener que memorizar poemas, docentes que definen como "malos profesores" y actividades de evaluación que desmotivan.

La reflexión conjunta sobre las prácticas docentes en el ámbito literario que han vivido los estudiantes, permite, por un lado, obtener mayor información so- 
bre su perfil literario, entender un poco más cómo han llegado a ser el lector que son, qué les ha conducido hasta aquí. Por otro lado, hacerles valorar prácticas docente les obliga a ser críticos y a pensar por qué algunas estrategias didácticas funcionan y otras, en cambio, no, y qué tienen en común aquellas experiencias que han considerado buenas y aquellas que han considerado malas.

\section{Propuestas de actuación en el campo de las textualidades multimodales para mejorar la competencia literaria}

Las sesiones de reflexión han constatado aquello que como profesoras ya intuíamos desde el atril, y es que los alumnos no tienen el perfil literario que suponíamos ni sus hábitos de lectura son los deseables. Estamos dotando a los estudiantes de estrategias y recursos para trabajar la literatura con sus futuros alumnos, con discursos sobre didáctica, que difícilmente podrán llevar a cabo porque les falta aquello más esencial: un bagaje literario, una experiencia que les permita interiorizar y aplicar los conceptos de la didáctica de esta materia tan vivencial. Si no vives, ni sientes la literatura, difícilmente podrás llevarla al aula con éxito. Podríamos dedicar páginas y páginas a lamentarnos sobre la realidad que habita las aulas de los grados de Educación Infantil y Primaria y discutir si se trata de una cuestión generacional o no; pero seguiríamos con el mismo problema. Después de analizar la situación real, es momento de tomar medidas al respecto. Mientras los planes de estudio no incluyan una formación literaria del futuro maestro para acabar de perfeccionar su perfil de lector literario, proponemos una serie de medidas que contribuyan a mejorar la competencia literaria de los estudiantes, a través de actividades y estrategias de educación estética y literaria desde la única asignatura de carácter literario, a saber, didáctica de la literatura infantil, en el caso del grado de Educación Infantil, y didáctica de la literatura infantil y juvenil, en el caso del grado de Educación Primaria.

Lo primero que es necesario conocer son sus gustos culturales, sus hábitos de ocio, qué les interesa, para luego poder acercar la literatura a su terreno. Tenemos una idea bastante clara de su perfil literario, sus hábitos de lectura y su contexto generacional. Éste último gracias, en parte al estudio de J. Ferrés (Ferrés, 2000), que analiza cómo los jóvenes han crecido en la denominada sociedad del espectáculo. Ésta potencia la sensorialidad audiovisual, la narratividad, la 
dinamicidad -todo sucede rápidamente y el zápping ya no es una actitud frente al televisor, sino frente a la vida-, la emotividad que está siempre presente y su respuesta no es reflexiva, es inmediata: "me gusta" o "no me gusta", y la sensacionalidad que se consigue a través de medios elementales. Por esto, se dice que las nuevas generaciones son consumidoras compulsivas de imágenes, que necesitan la estimulación permanente, que no toleran el estaticismo, la lentitud ni el silencio, que anteponen la concreción a la abstracción, la intuición a la reflexión y que contemplan más que piensan. Todas estas actitudes se han visto potenciadas en los últimos años con la comercialización masiva de smartphones, que se han convertido en una herramienta para todo: conectarse con los amigos, participar de las redes sociales, gestionar el correo electrónico, leer documentos de clase, consultar el Moodle del curso, etc. A partir de estas premisas se entiende mejor la dificultad de afrontar una lectura tranquila, silenciosa y reflexiva.

Si tenemos en cuenta todos estos elementos que pueden condicionar, y muy a menudo condicionan, la actitud de los estudiantes frente a la literatura, estamos preparados para hacer propuestas estratégicas que contribuyan a mejorar su competencia literaria, a pesar de no tener un espacio dentro del plan de estudios para dedicarnos a ello.

A continuación esbozaremos algunas propuestas que pretenden contribuir a la competencia literaria de los alumnos, sin perder de vista el marco que les da cabida: la asignatura de didáctica de la literatura infantil y juvenil.

1) El uso de la red social Goodreads como herramienta para fomentar la lectura en el aula. Goodreads es una red social destinada al ámbito literario. Sus participantes elaboran un perfil a partir de sus lecturas, pueden establecer amistad con otros participantes, ver sus lecturas, recomendar libros y valorarlos. Esta red social tiene disponible una aplicación para dispositivos móviles y tabletas, con lo cual se adapta a la manera de comunicarse de los estudiantes. Se propone en clase una lista de lecturas recomendadas y a medida que los alumnos van realizándolas, las van incorporando a su perfil, junto con una valoración y una crítica, que los demás pueden ver y comentar. Así se va tejiendo una red de lecturas recomendadas, críticas, valoraciones y comentarios que enriquece mucho el bagaje literario de los estudiantes. Esta herramienta puede acabar vertebrando una parte muy importante de las acciones del aula, cohesiona el grupo y hasta puede incorporarse a la evaluación de la asignatura. 
2) La plataforma web Storybird como herramientas para desarrollar la creatividad literaria. Se trata de una web que permite escribir historias y escoger ilustraciones para acompañarlas. Storybird permite gestionar desde un rol de profesor hasta treinta y cinco alumnos o trabajos (si se hacen en grupo) y hacer un seguimiento de todo el proceso de elaboración que siguen los estudiantes. En nuestro caso, hemos utilizado este recurso para plantear en clase la adaptación de un clásico de la literatura infantil y/o juvenil, hacer una reescritura escueta e ilustrarla con imágenes que ofrece la web. Finalmente, cada alumno o grupo de alumnos presenta la reescritura del clásico al resto de la clase, para fomentar las habilidades orales.

3) La incorporación de la herramienta multimodal del booktrailer en sustitución de la presentación oral de los libros del seminario de lectura. Dicha herramienta posibilita mejorar la competencia literaria de los alumnos, puesto que demanda la capacidad de hacer un buen análisis y ser capaz de transferir los resultados de éste y su posterior valoración en una herramienta multimodal. Los alumnos, agrupados en parejas, deben seguir las siguientes fases: planificación (ficha de análisis y story board), realización del vídeo y presentación. Como señala Rosa Tabernero, el booktrailer "puede convertirse en un instrumento de promoción de la lectura en el ámbito de la Web 2.0. tanto desde la perspectiva de la recepción como desde la creación." (Tabernero, 2013, p. 215). El proyecto de creaciones de booktrailers realizado por nuestros alumnos ha propiciado el trabajo simultáneo de varias capacidades y ha contribuido a mejorar varias competencias.

4) Las rutas literarias se inscriben en un enfoque comunicativo de la enseñanza de la lengua y la literatura centrado en el desarrollo de las habilidades orales, escritas y multimodales, y permiten relacionar territorio, literatura y cultura. En la mayor parte de propuestas educativas de rutas literarias se parte de "lugares literarios", que permiten vinculaciones biográficas y/o culturales con escritores o con fragmentos de sus creaciones. Sin embargo, también se pueden asociar paisajes naturales o urbanos con corpus literarios, a partir de la vinculación de elementos del paisaje con una selección de textos que favorezca un acercamiento diacrónico y multicultural sobre un motivo o tema literario. A modo de ejemplo, véase la propuesta sobre una ruta literaria centrada en las esculturas, relieves y ornamentos en forma de dragón situados en calles y casas de Barcelona (Díaz-Plaja, Prats, 2013). Nuestra experiencia se inscribe en la segunda posibilidad 
de ruta: el curso 2013-14, los alumnos participaron en una ruta con los textos preparados por las profesoras (Díaz-Plaja, Prats, 2014). La participación en estas actividades ha favorecido un acercamiento a la educación literaria desde una perspectiva interdisciplinar.

Como anunciamos al inicio, todas las propuestas giran en torno a la incorporación de herramientas digitales en la enseñanza-aprendizaje de la literatura, pero sin perder de vista que "el maneig de les noves tecnologies mai no és un fi en si mateix, sinó un instrument per eixamplar les nostres possibilitats de coneixement i de socialització." (Jover, 2007, p.85). En el mismo sentido, Borràs (Borràs, 2003) también defiende aprovechar la nueva realidad de internet para ampliar los conceptos de la estética de la recepción literaria para una educación estética en que la interactividad y la participación del alumno como lector le permita construir sus gustos y preferencias literarias.

Asimismo, Gemma Lluch (Lluch, 2014) realizó un estudio sobre los espacios virtuales que utilizaban los jóvenes de entre 13 y 29 años para hablar de libros, lecturas y autores. En su investigación, las redes de comunicación virtual como el Twitter y los blogs se conciben como un fenómeno de comunicación social pero sobre todo como una herramienta para la promoción de la lectura entre los más jóvenes.

Asimismo, las propuestas expuestas contienen las textualidades multimodales, como elemento clave para la educación literaria del alumnado: desde la mini ficción, el soporte audiovisual, la fotografía hasta trabajar sobre distintas versiones de un mismo texto. $Y$ es que:

La especificidad del discurso literario (especialmente por sus componentes intertextuales e hipertextuales) hace que la educación literaria, la recepción y la formación lectora constituyan un ámbito en que los recursos y procedimientos de la web 2.0 resulten particularmente efectivos para ampliar la competencia literaria, una de las más complejas por la diversidad de componentes que la integran. (Arbonés et al., 2014: 102)

De este modo, estas propuestas contienen la multimodalidad y la conectividad como elementos centrales, propios de la web 2.0, cuya utilización acaba beneficiando también el propio proceso de alfabetización interdisciplinaria de los estudiantes. Estas tareas sobre textualidades multimodales tienen una inci- 
dencia clara en la educación literaria de los estudiantes (recepción y producción) y además ayuda a desarrollar la capacidad de multimodal de los profesores en formación inicial, pues los ayuda a comprender, interpretar, reflexionar y ampliar su corpus literario (Arbonés et al., 2014).

\section{Conclusiones}

A lo largo de estas páginas, hemos analizado el perfil literario y los hábitos de lectura reales de los alumnos de los grados de Educación Infantil y de Educación Primaria de la Universidad de Barcelona. A partir de sesiones reflexivas con los estudiantes hemos constatado que el lector real, que frecuenta las clases, dista mucho del lector ideal a quien parecen ir dirigidas las asignaturas de didáctica de la literatura, que contemplan los planes de estudio, cuyo objetivo es convertir al supuesto buen lector literario en un buen mediador, gracias a estrategias, actividades y recursos didácticos. Asimismo, se ha considerado oportuno reflexionar sobre los recuerdos de experiencias, buenas y malas, con la literatura para entender mejor la complejidad de la problemática e intentar aprovechar las buenas experiencias para integrarlas en las propuestas de actividades y para tenerlas en cuenta en su futura actuación docente.

Una vez analizada la realidad, hemos propuesto cuatro actuaciones docentes para incorporarlas al curso de didáctica de la literatura para mejorar la competencia literaria a la vez que se sigue trabajando la literatura infantil y/o juvenil. Las cuatro propuestas - el uso de la red social Goodreads, la plataforma web Storybird, la creación de un booktrailer y la realización de una ruta literaria-, se insertan en el contexto social y generacional de los estudiantes, puesto que, los espacios virtuales congregan adolescentes y jóvenes para hablar de libros, lectura y autores (Lluch, 2014).

Las respuestas de los estudiantes han sido bastante satisfactorias, han participado con interés, han aumentado su competencia literaria y han tomado conciencia del largo camino que les queda por recorrer antes de llegar a ser unos buenos mediadores entre los libros y sus futuros alumnos. A través de las distintas propuestas se ha conseguido acercar el discurso literario al día a día de los estudiantes, gracias al uso de instrumentos virtuales, que son cercanos a los dispositivos y plataformas que ocupan sus ratos de ocio. De este modo, se ha 
conseguido mejorar notablemente la competencia literaria de los alumnos, así como su actitud hacia la literatura y su motivación. 


\section{Referencias}

ARBONÉS, C.,et al. Textualidades multimodales, conectividad y redes 2.0 en el aula: sobre la educación literaria y el profesorado en formación. En: DE AMO, J. M., CLEGER, O, MENDOZA, A.(eds.). Redes hipertextuales en el aula. Literatura, hipertextos y cultura digital. Barcelona: Octaedro, 2015, p. 97-120.

BORRÀS, L., De la estética de la recepción a la estética de la interoperatividad. Notas para una hermenéutica del a lectura hipertextual. Revista Hermeneia, 2003.

http://www.uoc.edu/in3/hermeneia/sala de lectura/estetica interactividad.htlm. Consultado en mayo 2006.

COLOMER, T., MUNITA, F. La experiencia lectora de los alumnos de Magisterio: nuevos desafíos para la formación docente. Revista Lenguaje y Textos, Barcelona, núm. 38, p.37-46, noviembre 2013.

COLOMER, T., Entre la normalitat i el desinterès: els hàbits lectors dels adolescents. En: COLOMER, T. (coord.). Lectures adolescents. Barcelona: Graó, 2008, p. 19-58.

DÍAZ ARMAS, J. Lectura literaria y formación inicial: Creencias del profesorado sobre el texto y su lector. En: MENDOZA, A. (coord.). Textos entre textos: las conexiones textuales en la formación del lector. Barcelona: Horsori, 2008, p. 177-190.

DÍAZ-PLAJA, A., Entre llibres: la construcció d'un itinerari lector propi en l'adolescència. En: COLOMER, T. (coord.). Lectures adolescents. Barcelona: Graó, 2008, p. 117-148.

DÍAZ-PLAJA, A., PRATS, M. Recordar, aprender, practicar: qué sabe y qué debe saber un futuro maestro. Revista Lenguaje y Textos, Barcelona, núm. 38, p.19-28, noviembre 2013.

FERRÉS, J. Educar en una cultura del espectáculo. Barcelona: Paidós, 2000.

JOVER, Guadalupe. Un món per llegir. 1a edición. Barcelona: Edicions Rosa Sensat, 2007. LARRAÑAGA, E., YUBEROS, S., CERRILLO, P. Estudio sobre los hábitos de lectura de los universitarios españoles. Madrid: SM, 2008.

LLUCH, G. (ed.). Las lecturas de los jóvenes: Un nuevo lector para un nuevo siglo. Barcelona: Anthropos, 2010.

LLUCH, G. Jóvenes y adolescentes hablan de lectura en la red. Revista Ocnos, núm. 11, p. 7-20, 2014.

MANRESA, M. Els hàbits lectors dels adolescents: Efectes de les actuacions escolars en les práctiques de la lectura. Tesis doctoral. Barcelona: Universitat Autònoma de Barcelona, 2009.

MARGALLO, A. M., Entre llegir com a nois i noies i llegir com a adults: el paper del "best-sellers". En: COLOMER, T. (coord.). Lectures adolescents. Barcelona: Graó, 2008, p.219-236. 
MENDOZA, A. La educación literaria. Bases para la formación de la competencia lecto-literaria. Málaga: Algibe, 2004.

ROMERO OLIVA, M. F., TRIGO, E. Las rutas literarias: una estrategia de carácter competencial para la educación literaria dentro y fuera del aula. Revista Lenguaje y tetxos, núm. 35, p. 63-71, 2012.

TABERNERO, R. El booktrailer en la promoción de la lectura del relato. Quaderns de Filologia. Estudis literaris, vol. XVIII, p. 211-222, 2013. 